\title{
TERCER PREMIO CONCURSO NACIONAL DE IDEAS PROYECTO URBANO COSTERO, CORRIENTES CAPITAL
}

Repetto, Julieta; Sánchez, Lorena; Alcalá, Laura y López, Silvina

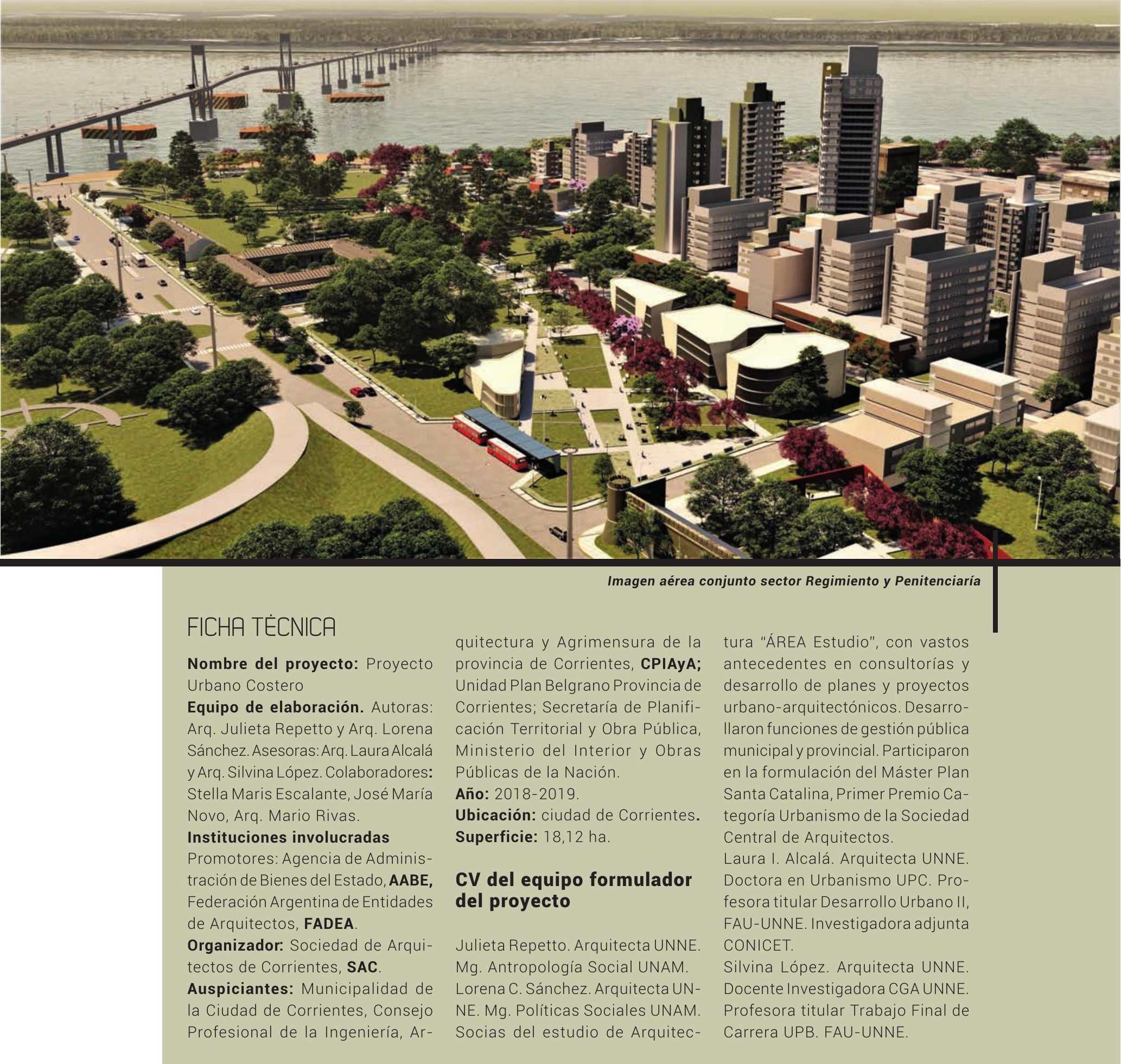


TERCER PREMIO CONCURSO NACIONAL DE IDEAS PROYECTO URBANO COSTERO, CORRIENTES CAPITAL

\section{RESUMEN}

El artículo desarrolla los aspectos principales de la propuesta presentada por las autoras al Concurso Nacional de Ideas Proyecto Urbano Costero para la ciudad de Corrientes, Argentina. La formulación de la propuesta fue realizada desde una perspectiva crítica que se tomó la libertad de no responder las propias bases del concurso, fundada en tres premisas estratégicas: el respeto por el paisaje cultural; un sistema de espacios públicos, accesibilidad universal y diseño sustentable y la primacía del interés público.

\section{PALABRAS CLAUE}

Concurso Proyecto Urbano Costero; paisaje cultural; sistema de espacios públicos; interés público.

\section{ABSTRACT}

The article develops the main aspects of the proposal presented by the authors to the National Ideas Contest "Corrientes City Coastal Urban Project". The formulation of the proposal was made from a critical perspective that took the liberty of not answering the Contest's own bases, based on three strategic premises: respect of the cultural landscape; a system of public spaces, universal accessibility, and sustainable design and the primacy of the public interest.

\section{KEYWORDS}

Coastal Urban Project contest; cultural landscape; system of public spaces, public interest. 
más menos tolerancia de un $10 \%$, conforme el porcentaje de cesión total promedio en los tres predios para utilidad pública no resultara inferior al $60 \%$ de la superficie total que intervenir.

\section{Sustento ideológico y técnico de la propuesta}

Un concurso de ideas abre siempre la oportunidad de discutir creativamente escenarios posibles de desarrollo urbano y el desafío de verificar en tiempos breves la factibilidad y el modelado de la propuesta. La decisión de participar obedeció a la posibilidad de plantear alternativas a la forma de desarrollo excluyente y exclusiva promovida por las bases. En desacuerdo con la manera en que se propuso el traspaso de tierras públicas de alto valor inmobiliario a manos de privados, cediendo con el suelo una altísima renta potencial producto del cambio en uso y edificabilidad, y en desacuerdo con el cambio normativo, tanto por la modalidad seguida como por los términos urbanísticos que no incluyeron la evaluación de sus impactos sociales, ambientales y funcionales, ni la vinculación de este sector con los otros sectores costeros.

Para el equipo del proyecto, desde el rol profesional y académico, el concurso constituyó la oportunidad y el desafío de demostrar que es posible introducir cambios y mejoras en la ciudad de una manera respetuosa de su patrimonio histórico y cultural, y sobre todo de su patrimonio inmobiliario. El cambio de usos, justificado por el tipo de actividades que quedaron insertas de manera obsoleta en la ciudad, exigía una clara vocación de servicio a la ciudad, no al negocio puramente especulativo

La participación en el concurso estuvo motivada entonces por la expectativa de que el Municipio pueda rever los términos en que hasta ahora ha concebido el denominado "Plan Costero", y en este sentido el equipo se tomó la libertad más que de responder a las bases, de interpelarlas a partir de tres premisas estratégicas.

\section{PREMISAS ESTRATÉGICAS}

\section{Respeto por el paisaje cultural}

Elárea del proyecto se reconoció como un paisaje cultural que respetar. El área fue partícipe de la construcción de la historia urbana de la ciudad íntimamente asociada al río Paraná Su origen, su desarrollo y su proyección futura comparten una relación indisociable con el río, que constituye uno de sus principales rasgos de identidad. En este marco, el proyecto asumió el desafío de repensar la línea de encuentro entre la ciudad y el río, donde se reconocieron puntos icónicos de la historia y el devenir urbano, el entorno natural de singular belleza y sobre todo las costumbres y cultura urbana que arraigan en el espacio público del borde costero.

Al ser la Costanera San Martín el tramo más antiguo de un borde ribereño que se extiende largamente hacia el norte y el sur, donde es posible pensar distintos tipos de desarrollo costero, la propuesta consideró pertinente preservar la configuración espacial actual del tramo, sin alterar sus principales rasgos identitarios: un tipo de paisaje, una escala urbana y una determinada forma de uso del espacio público, que ejercen gran poder de atracción sobre el visitante y enorgullece a su población. Se trata de un concepto de preservación activa, en la cual la conservación formal se apoya en la introducción de usos colectivos ampliados y permanentes. De este modo, en el predio del Puerto se propuso la conservación de las construcciones más características de su función primigenia pero con nuevos usos. En tanto los predios del Ejército y la Penitenciaría se consideran en conjunto con la cabecera del puente Gral. Belgrano como hito fundacional y sector signado por la memoria colectiva, por lo que se propuso reconvertir los recintos en un sector de nueva centralidad, reforzando su carácter de puerta de acceso a una ciudad abierta a la integración de la región, con el Chaco y el Mercosur.

\section{Sistema de espacios públicos, accesibilidad universal y diseño sustentables}

La puesta a disposición de la ciudad de predios que hasta el presente constituyen recintos que obstruyen continuidades urbanas e impiden la llegada al río se consideró una oportunidad para permitir la accesibilidad del ciudadano común al río, para coser tejidos y para reivindicar la centralidad de barrios postergados. Se consideró necesario abordar los tres predios en forma conjunta y como partes del sistema urbano que los contiene, con una visión integral y estratégica de la ciudad del futuro, donde cada una de estas piezas permitiría introducir nuevas funciones y servicios, recorridos alternativos y diversas actividades, 
además de propiciar la articulación y enriquecer el sistema de espacios públicos y verdes. En este sentido, a los parques existentes, Mitre y Camba Cuá, se incorporó el nuevo Parque de la Integración en el predio del Ejército. Una pauta prioritaria de la propuesta fue la de mejorar las condiciones de conectividad, irrigación y accesibilidad universal, tanto hacia el río como de los distintos sectores de la ciudad entre sí, generando nuevas alternativas de conexión y de descompresión de las vialidades en el centro histórico. Con este fin se propusieron operaciones de costura urbana. Así, se definieron bulevares en el predio del ejército con rotondas que permiten empalmar y articular con las distintas vías que allí convergen, se aporta una nueva salida de la Costanera al centro de la ciudad y se crea una nueva continuidad por debajo del arranque del puente, lo que supone una notable mejoría para la comunicación del sector sur, que en la actualidad depende exclusivamente de la costanera. Se produce la continuidad peatonal en todo el paseo costero y nuevas Ilegadas al borde y miradores, prolongando las calles transversales al río.

Estas operaciones permitieron reconfigurar el Paseo Arazaty, el que eventualmente con la peatonalización temporal del primer tramo de la Av. 3 de Abril podría ser utilizado de forma conjunta con el Parque de la Integración, poniendo a disposición de la ciudad un espacio recreativo de gran escala, sin interrumpir la conectividad del sector. Las nuevas calles fueron concebidas integralmente, con espacio vehicular y peatonal, incluyendo continuidad de niveles, rampas, cruces y adecuada iluminación y arbolado. La red peatonal incluye recorridos complementarios alternativos, garantizando conexiones que no superan distancias mayores a $200 \mathrm{~m}$.

Pensando en una ciudad más sus tentable y atendiendo a la demanda de mejoramiento de la accesibilidad a la costanera, se propicia el mayor uso de transporte público terrestre y fluvial, así como de medios de movilidad no contaminantes. Se propuso la incorporación de un circuito de bicisenda que amplía y se vincula con el existente, de un nuevo recorrido costero del transporte público urbano, de un circuito y estaciones fluviales que ligan la ribera de toda la ciudad y de nuevas estaciones de transferencia multimodales.

Se contempló la reorganización y ampliación de las plazas de estacionamiento, de manera que no ocupen los mejores espacios de circulación con visuales al río ni condicionen la oferta necesaria de transporte público en toda la costa. Se propuso ubicar la actual línea de estacionamiento a $45^{\circ}$ a lo largo de la costanera sobre la banda izquierda, junto al parterre, lo que permitirá recuperar la banda sobre el río para la circulación de ciclistas, patinadores y skaters, para dar respuesta así a una demanda creciente, acorde con parámetros de mayor seguridad y puesta en valor de las personas por sobre los vehículos. Por otro lado, en el sector del Puerto, más condicionado por el escaso ancho disponible, se proponen estacionamientos subterráneos.

El arbolado y la cobertura vegetal son respetados en la propuesta, los ejes viales y la implantación de los nuevos edificios y actividades preservan el arbolado existente e incorporan nuevos ejemplares de especies autóctonas para reforzar la identidad de los espacios verdes y de las nuevas vialidades. En cuanto a la materialización de los espacios públicos, se propuso un diseño bioclimático, con incorporación de reservorios de agua, aspersores en circulación peatonal, control de la superficie impermeable, solados absorbentes, superficies verdes, arbolado y espacios semicubiertos. Toda la iluminación del espacio público, así como los cargadores de equipos electrónicos y calentadores de agua, contemplan la utilización de energía solar.

Respecto de las nuevas edificaciones, los edificios se implantaron de tal manera que se evita formar una pantalla que impida la continuidad del viento como moderador climático, y se previó incorporar en los predios los elementos tecnológicos necesarios para lograr el factor de impermeabilización cero, utilizando cubierta vegetal, retardadores pluviales, entre otros.

\section{Interés público}

Los intereses convergentes del mercado y de la demanda social por el uso público y recreativo que se suscitan en el borde ribereño tienen la oportunidad y el compromiso de ser atendidos con base en el interés colectivo, con criterios de integralidad, equidad y sustentabilidad, por tratarse de predios de dominio del Estado. Al ser predios con alto valor inmobiliario y reservas preciadas de suelo público, su gestión estratégica debe garantizar mecanismos de recupero y redistribución para las áreas más desfavorecidas de la ciudad, en el marco de lo establecido por la Constitución Provincial en el Art. 41 y la Carta Orgánica Municipal. 


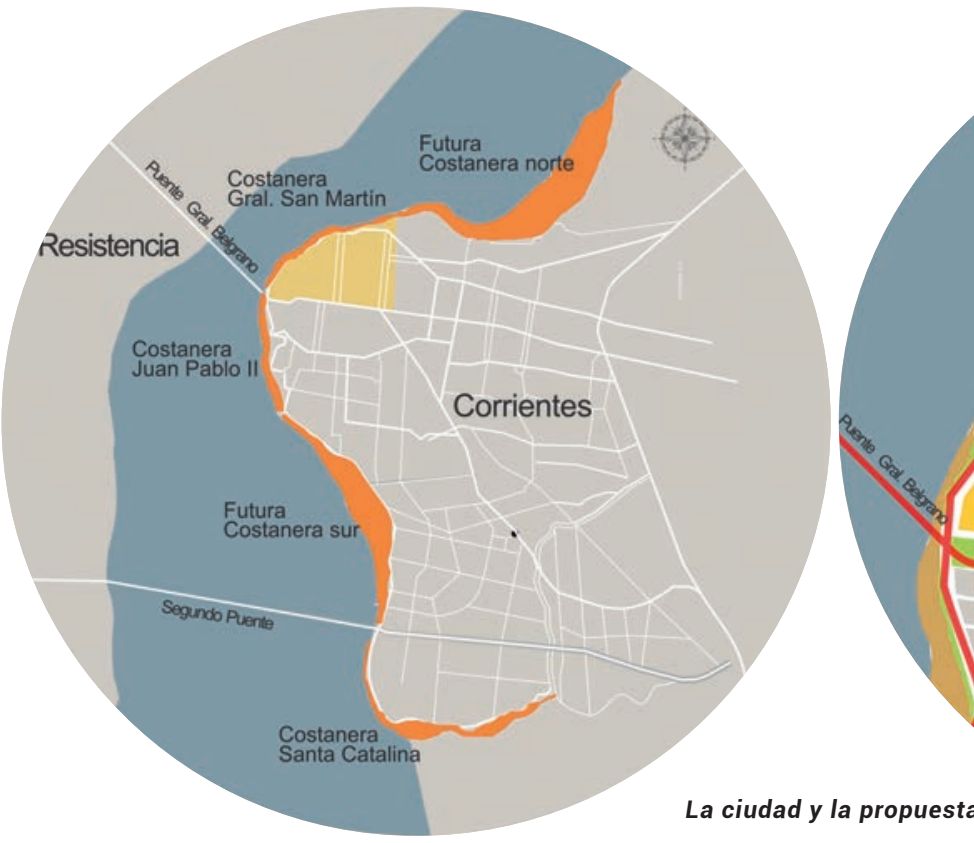

El desafío de poner en valor el mayor patrimonio paisajístico y recreativo de la ciudad no puede prescindir de la opinión y visión de los ciudadanos de Corrientes. Es por ello que esta propuesta abreva de las demandas y cuestionamientos surgidos desde distintos sectores sociales y profesionales, y toma en cuenta los principales deseos manifestados en oportunidad de la discusión de esta problemática en los talleres que tuvieron lugar en noviembre y diciembre de 2018. Desde esta concepción, el proyecto propone la distribución de usos públicos y privados, de las actividades, densidades y edificabilidades, complementándolas en función de las características urbanas y potencialidades inherentes de cada subárea de intervención.

Con este criterio la propuesta asignó usos y edificabilidades di- ferentes de los planteadas en las bases de este concurso de ideas, sin por ello afectar significativamente el área de uso privado ni la edificabilidad previstos. El proyecto asignó el $67,7 \%$ de la superficie total de los tres predios para utilidad pública y el 32,3\% restante para utilidad privada, con una capacidad constructiva total levemente menor a la prevista por las bases del concurso.

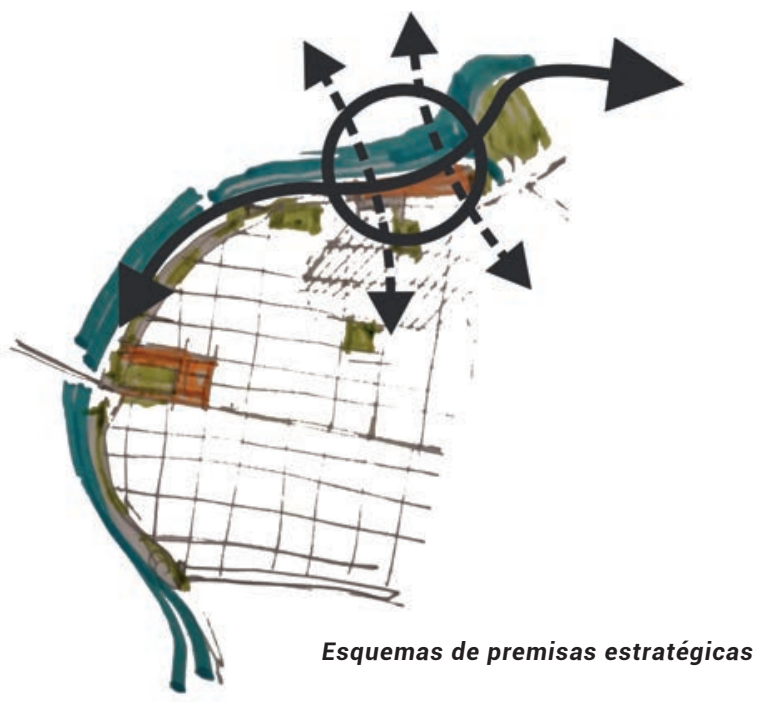

El Puerto constituye la oportunidad de recuperar la relación de la ciudad con el río y de religar el borde costero con el sector central de la ciudad.

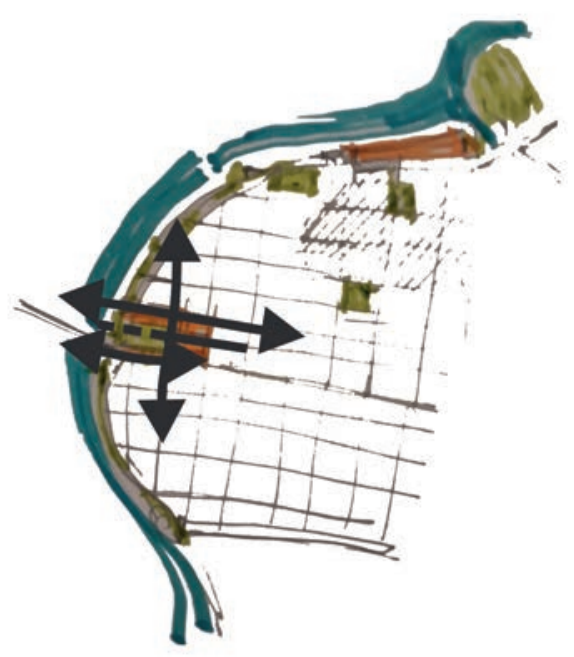

Las intervenciones en los sectores del Puerto y el Regimiento permiten completar la estructura urbana y favorecer las conexiones $\mathrm{N}$-S y E-O. 


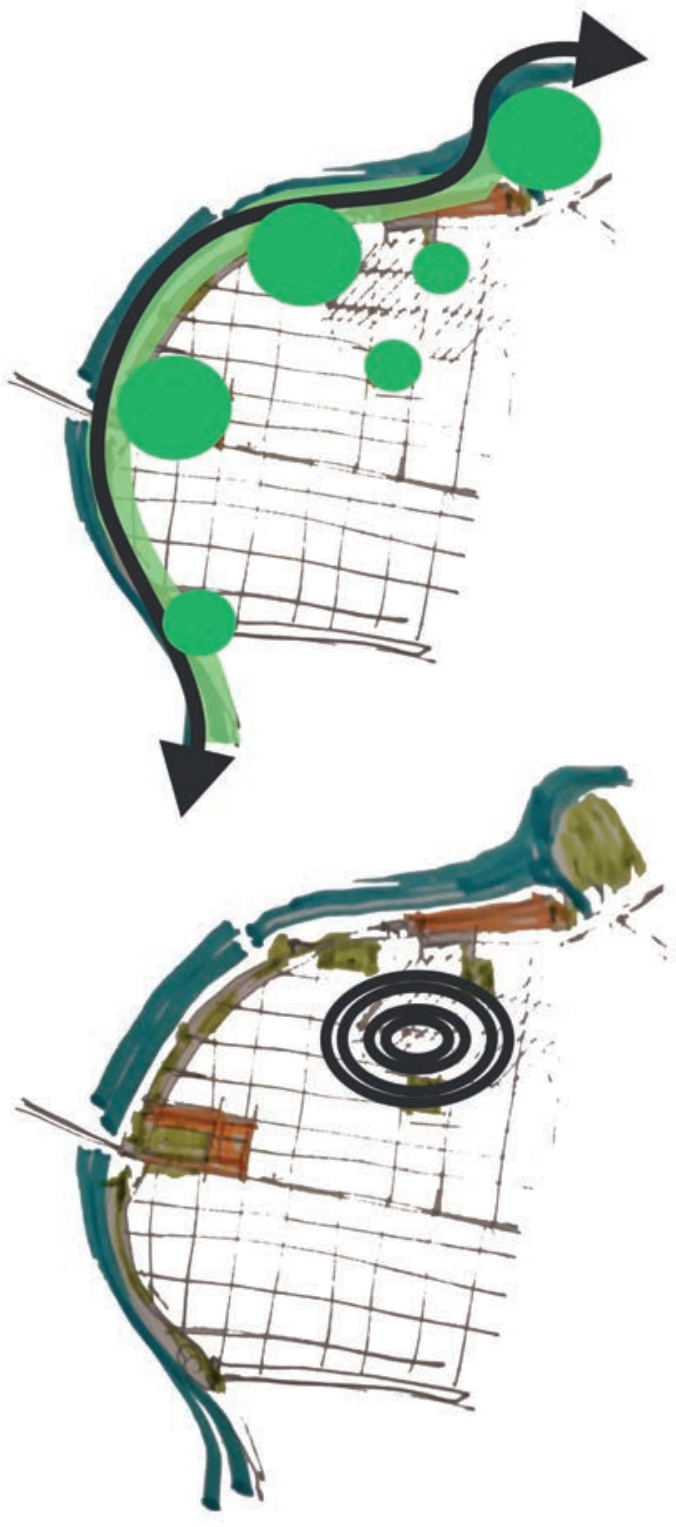

El nuevo Parque de la Integración generado en el predio del Regimiento, amplía y completa el sistemas de Parques y espacios verdes ribereños.

Esquemas de premisas estratégicas

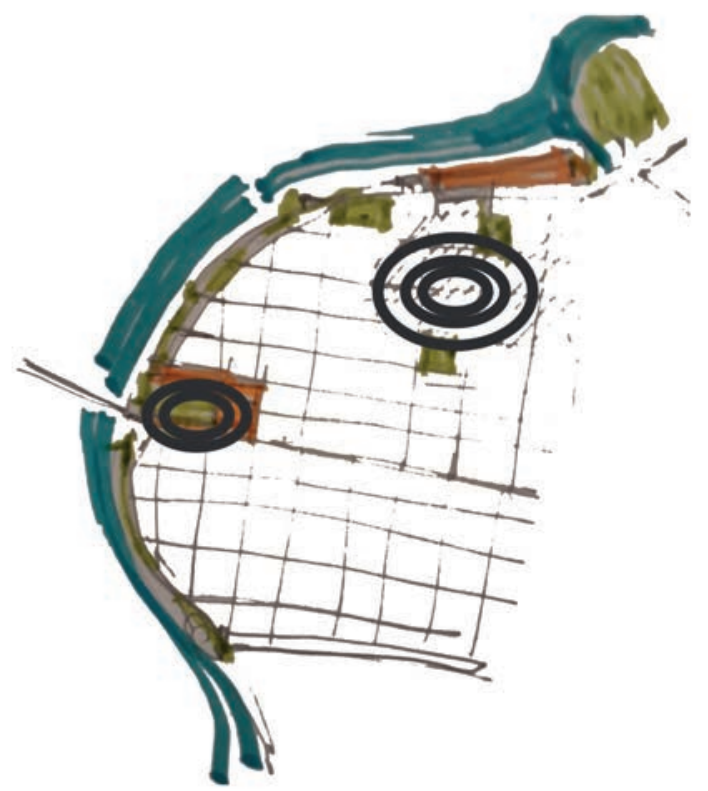

El conjunto del Regimiento y la Penitenciaría constituye la posibilidad de ganar para la ciudad suelo urbano hasta ahora denegado convirtiéndolo en un área de nueva centralidad que permitirá descomprimir el área central histórica.

Sintesis de asignación de áreas y edificabilidad

\begin{tabular}{l|c|c|c|c}
\multicolumn{1}{c|}{ PREDIOS } & SUPERFICIE & $\begin{array}{c}* \text { ÀREA DE } \\
\text { UTILIDAD PÜBLICA }\end{array}$ & $\begin{array}{c}* * \text { ÀREA DE } \\
\text { UTILIDAD PRIVADA }\end{array}$ & $\begin{array}{c}\text { EDIFICABILIDAD } \\
* * *\end{array}$ \\
\hline $\begin{array}{l}\text { Puerto } \\
\text { (Puerto y vías navegables) }\end{array}$ & $65.683 \mathrm{~m} 2$ & $74,0 \%$ & $26,0 \%$ & $24.500 \mathrm{~m}^{2}$ \\
\hline Regimiento & $96.969 \mathrm{~m}^{2}$ & $70,0 \%$ & $30,0 \%$ & $180.000 \mathrm{~m}^{2}$ \\
\hline Penitenciaría & $18.690 \mathrm{~m}^{2}$ & $32,0 \%$ & $68,0 \%$ & $73.970 \mathrm{~m}^{2}$ \\
\hline Total & $\mathbf{1 8 1 . 2 4 2} \mathbf{~ m}^{\mathbf{2}}$ & $\mathbf{6 7 , 7} \%$ & $\mathbf{3 2 , 2} \%$ & $\mathbf{2 7 8 . 4 7 0 \mathbf { m } ^ { 2 }}$ \\
\hline
\end{tabular}

* Nuevos espacios verdes parquizados. Incluye el espacio destinado a calles, equipamiento y otros usos a localizar en la superficie a ceder al municipio.

** Incluye las operaciones de nueva urbanización. Alberga la eficabilidad definida.

*** Referida a los nuevos emprendimientos y aplicada en el área de utilidad privada. 
PAUTAS

GENERALES

DE INTERUENCIÓN

EN LOS SECTORES

\section{Predio Puerto (sector puerto y vías navegables)}

El Puerto constituía la oportunidad de recuperar la relación de la ciudad con el río y de religar el borde costero en el punto central e histórico de la ciudad. Se planteó el desarrollo de un paseo costero que vincula la costanera actual, la estación de transporte público urbano, un nuevo Puerto Turístico (para embarcaciones de gran y mediano porte), una Estación Fluvial (del nuevo transporte público) y el Parque Mitre, con un carácter turístico, comercial, cultural y recreativo.

El Puerto es el borde ribereño del sector urbano más antiguo de la ciudad, incluido en los distritos

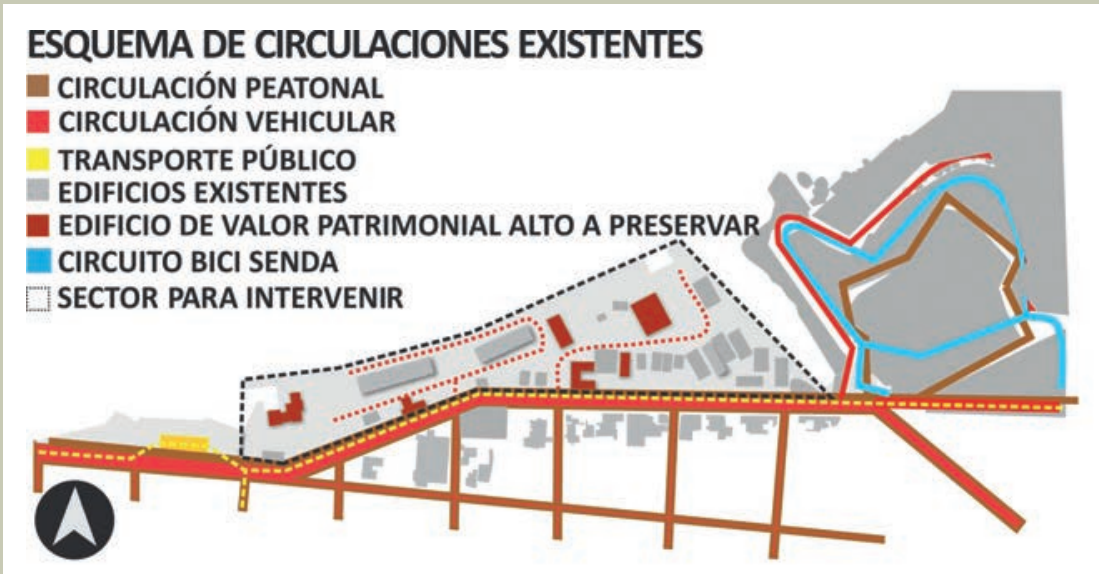

ESQUEMA DE CIRCULACIONES PROPUESTAS

- CIRCULACIÓN PEATONAL

- CIRCULACIÓN VEHICULAR

- CIRCUITO BICI SENDA

- EDIFICIOS EXISTENTES PARA RECICLAR

- EDIFICIO DE VALOR PATRIMONIAL ALTO A PRESERVAR

TRANSPORTE FLUVIAL

TRANSPORTE PÚBLICO

SECTOR PARA INTERVENIR

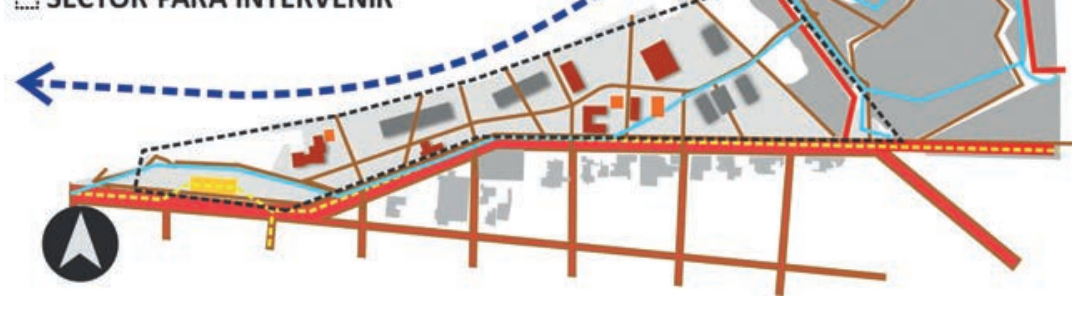

Esquemas de situación actual y propuesta para el sector Puerto

Centro Histórico Monumental (CHM) y Centro Histórico $(\mathrm{CH})$ del Código de Planeamiento Urbano, y por ello se propuso la conservación de las construcciones más características de su función histórica y de alto valor patrimonial, con espacios apropiados a los nuevos usos de puerto, actividades turísticas, sociales y culturales demandadas por la ciudadanía. El recorrido se concibe con una estética portuaria y naval, utilizando elementos que se encuentran en el predio (grúas, contenedores, boyas, anclas) y expresiones artísticas como esculturas y murales.

\section{Conectividad y movilidad}

Se planteó una continuidad peatonal con intervenciones en los extremos $\mathrm{N}$ y S. Al norte, se propuso el entubamiento parcial del arroyo Poncho Verde, lo que posibilita incrementar superficie de espacio verde, y un puente peatonal que vincula el $\mathrm{Pa}$ seo del Puerto con el Parque Mitre mejorando la accesibilidad al parque.

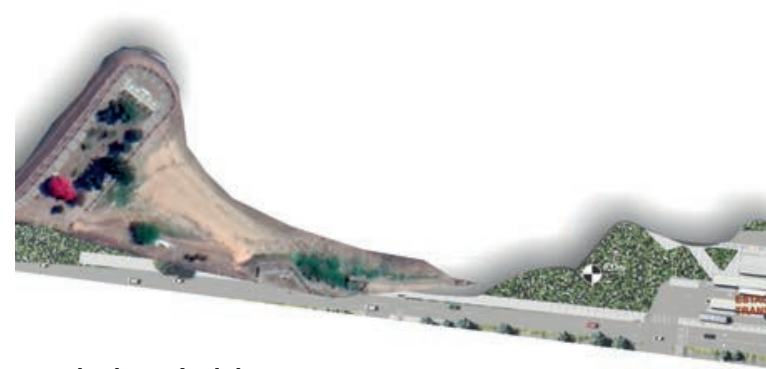

Planimetría del sector

Puerto y Vías Navegables

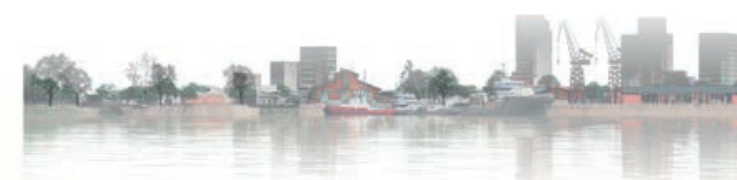

Imagen aérea y perfil

del sector Puerto $y$ Vías Navegables

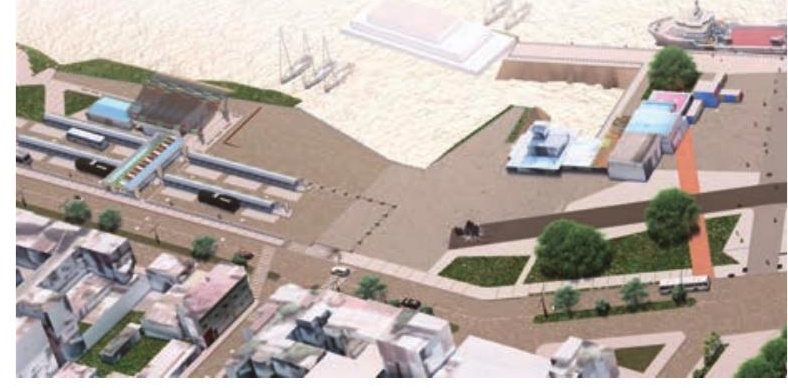


En la continuidad hacia la estación de transferencia de transporte público, se incorporó una nueva senda peatonal que bordea el río y permite la vinculación peatonal con el paseo Costanera

A lo largo del predio se configuraron nuevas llegadas peatonales y visuales al borde en sentido E-O, prolongando la continuidad de las calles transversales. Se previó un estacionamiento vehicular en playa subterránea, lo que permitió proponer una bicisenda en todo el paseo Costanera y conectar el circuito del Parque Mitre con el de la Costanera Juan Pablo II.

Las intervenciones propuestas aportan a la consolidación de un nodo multimodal de transporte, que permitirá complementar los distintos modos de movilidad existentes e incorporar la movilidad por el río, ya que la estación fluvial proyectada prevéla conexión con otras estaciones ubicadas en la ribera por medio de embarcaciones de pequeño porte.

\section{Usos y edificabilidad}

Debido a los usos que se plantean para el predio, al alto valor histórico y patrimonial del sitio y de las construcciones existentes que se propone reciclar y poner en valor, se consideró inconveniente la introducción de usos residenciales, puesto que además de limitar el espacio de uso público, generaría una densidad incompatible con la situación actual de congestión del centro de la ciudad. Se rescató la idea de playón portuario, a partir de ahora abierto al público, los gal pones característicos, los contenedores adaptados para resituar y dotar de condiciones nuevas de confort y orden a las actividades comerciales complementarias al nodo transporte y a la actividad turística.
El proyecto se planteó en etapas, considerando necesario en una primera mantener la función y ubicación de Vías Navegables en un espacio más reducido que el actualmente ocupado, hasta que se pueda reubicar en la zona adyacente al futuro puerto comercial. Se propuso reciclar los principales galpones para Espacio del Carnaval, Museo de Arte Moderno (luego del traslado de Vías Navegables), y poner en valor como íconos visuales del paisaje portuario las grúas. Se incluyeron
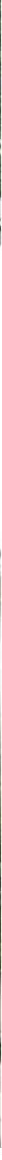

ADNea Revista de Arquitectura y Diseño del Nordeste argentino 


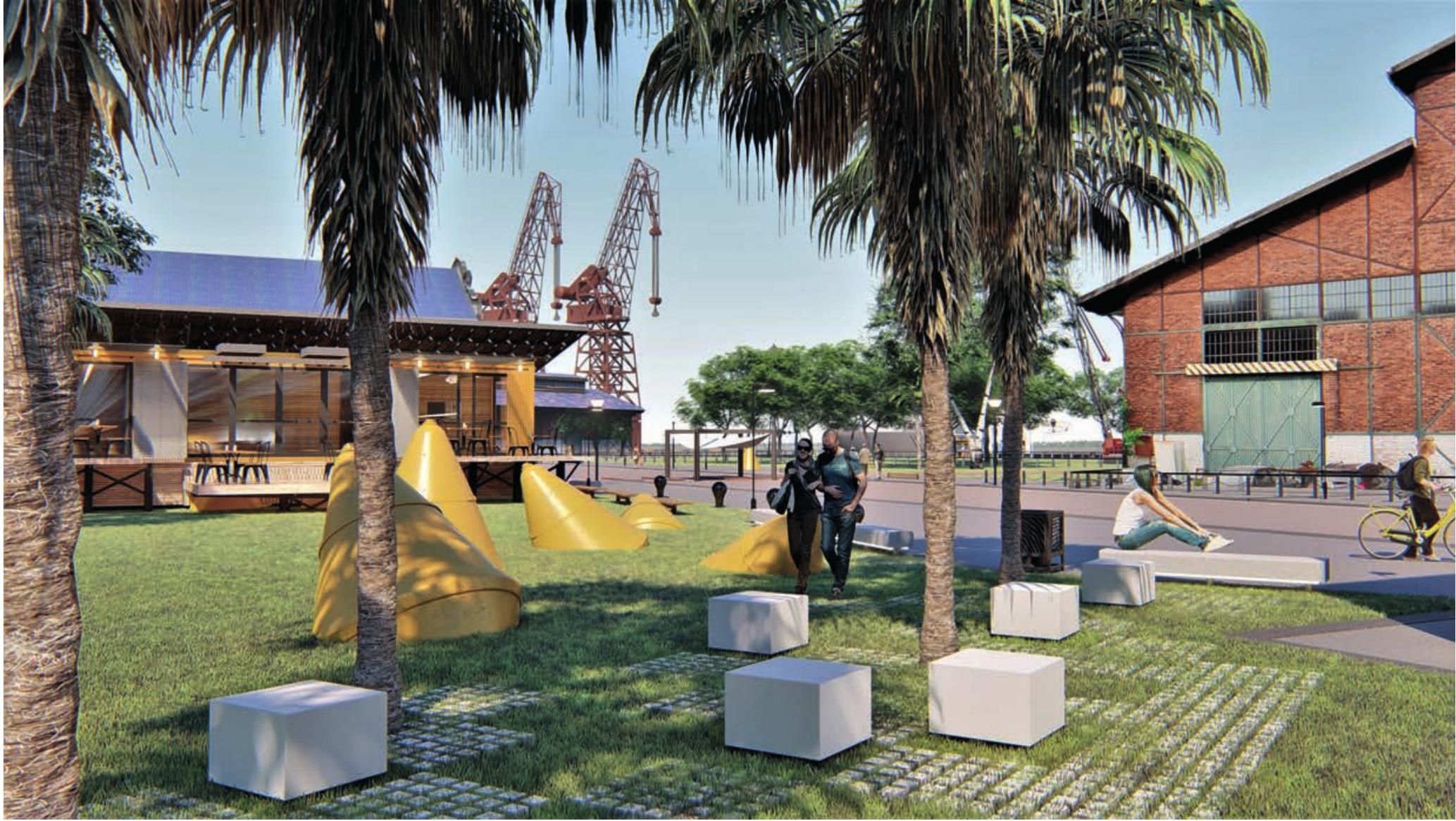

Imagen peatonal sector Vías Navegables

esculturas de escala durante todo el paseo, con remembranzas a un pasado obrero naval, conjugado con intervenciones más innovadoras, como una atracción turística que mediante un ascensor panorámico permite tener una perspectiva en altura de toda el área.
La propuesta asignó como área de utilidad privada para el desarrollo de actividades comerciales y complementarias de gestión público-privada el $26 \%$ de la superficie del predio, incluyendo superficie aprovechable en edificios de alto valor patrimonial. Se introdujeron actividades comerciales y gastronómicas en módulos concesionables (contenedores, estructuras removibles y efímeras) acompañando el paseo portuario proyectado en el $18 \%$ de la superficie del predio. En cuanto a la edificabilidad aplicada en el área de utilidad privada, se asignaron a

Imagen peatonal sector Puerto

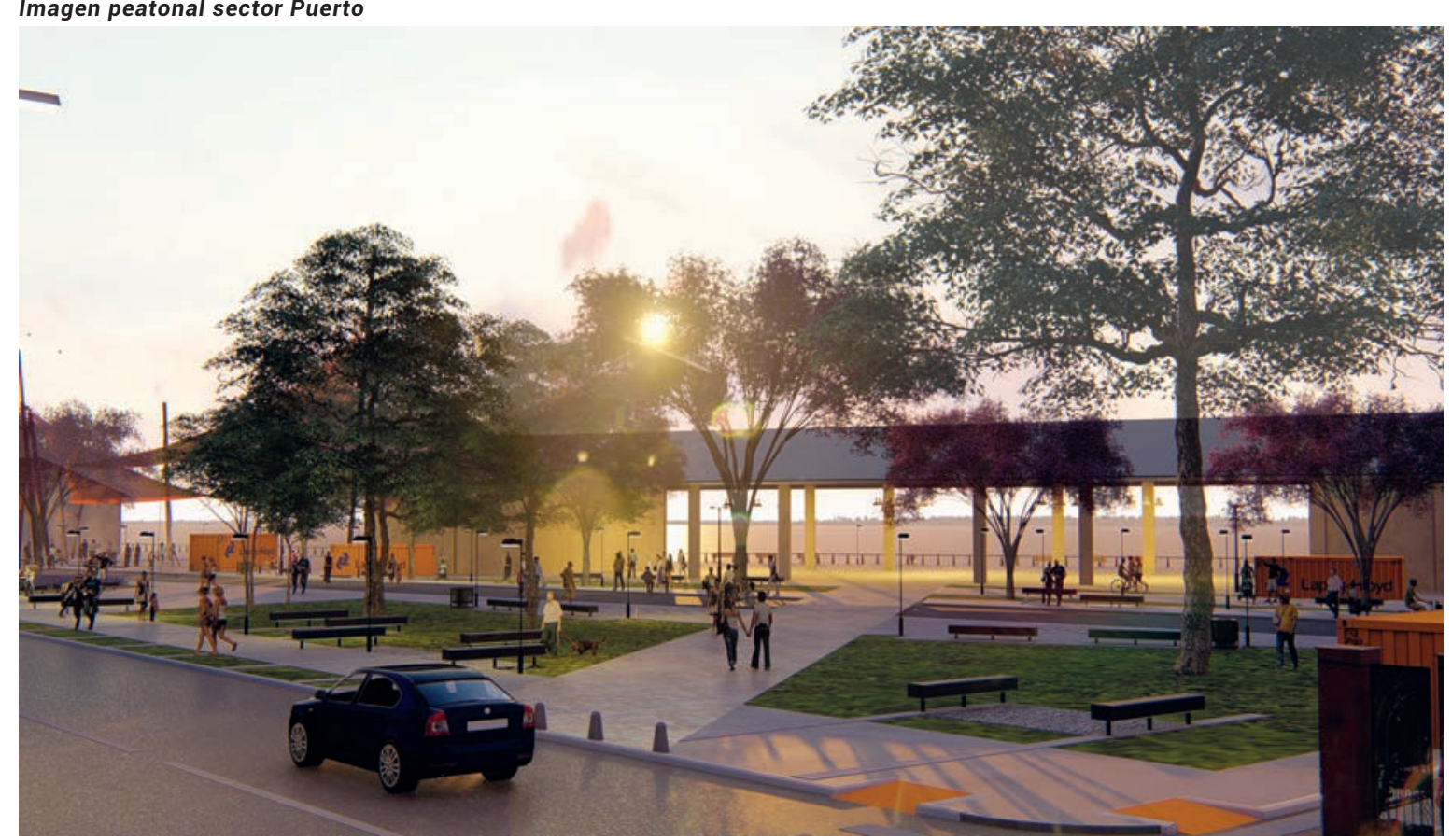


actividades hoteleras, comerciales y complementarias $6800 \mathrm{~m}^{2}$ existentes en edificios de valor patrimonial que serán objeto de intervenciones de preservación y puesta en valor en el marco de la normativa vigente en el Distrito Casco Histórico $(\mathrm{CH})$.

Se asignaron $7600 \mathrm{~m}^{2}$ de superficie para las actividades comerciales y gastronómicas en módulos concesionados, y $6700 \mathrm{~m}^{2}$ a un estacionamiento subterráneo de gestión público-privada propuesto en el sector Vías Navegables, lo que representa la incorporación de una superficie equivalente al $10 \%$ del predio.

\section{Predio Regimiento}

El conjunto del Regimiento y la Penitenciaría constituyen para la ciudad la posibilidad de ganar suelo urbano convirtiéndolo en una nueva centralidad. Se propuso convertir el sector conformado por el predio del Ejército, la cabecera del puente Gral. Belgrano y la Av. 3 de Abril en la nueva puerta de ingreso a una ciudad que se abre a la integración de la región, y reconvertir el recinto signado por un uso restringido a la población y la memoria colectiva (tanto de la represión de la dictadura militar como de los caídos en Malvinas) en un parque urbano y en un sector de nueva centralidad, que incorpora usos institucionales / administrativos, culturales, comerciales y residenciales.

\section{Conectividad y movilidad}

Para modificar la situación de barrera urbana que genera la gran "solicitación" de algunos pocos ejes viales, la escasa accesibilidad al eje costero y una mala conectividad entre el área central y la expansión sur de la ciudad, se propuso la intervención en los ejes viales de todo el sector.

Se proyectó la apertura de un bulevar en sentido N-S que atraviesa el predio del Ejército, pasa por debajo de la cabecera del puente y da continuidad a la calle Díaz de Vivar, incluyendo rotondas que permitan empalmary articular con las distintas vías convergentes a ella. Ofrece una mejora notable en la vinculación N-S y la descompresión de la solicitación funcional sobre el eje costero, y generará además una alternativa de acceso al puente Gral. Belgrano. Se complementa con otro bulevar en sentido E-O (perpendicular al primero) desde la costanera Gral. San Martín hasta la calle Padre Borgatti continuando en la calle Moreno, aportando un nuevo vínculo entre la costanera y el centro de la ciudad.

En atención a la demanda existente y a nuevos usos propuestos, se mejora la accesibilidad y oferta de transporte público urbano e interprovincial, incluyendo una nueva estación de transferencia que se suma a la estación fluvial ubicada a la altura de la calle Edison. También se da continuidad a la bicisenda proyectada en la costanera Gral. San Martín hasta la existente en la costanera Juan Pablo II.

\section{Usos y edificabilidad}

El proyecto incorporó al sistema de espacios verdes del borde costero el nuevo Parque de la Integración, que incluye un anfiteatro aprovechando los niveles propios del terreno y consolida el aterrazamiento hacia la costanera. Se reconfiguró el Paseo Arazaty, que eventualmente (con la peatonalización temporal del primer tramo de la Av. 3 de Abril) podría ser utilizado de forma conjunta con el Parque de la Integración, poniendo a disposición de la ciudad un espacio recreativo de gran escala, sin interrumpir la conectividad del sector.

\section{ESQUEMA DE CIRCULACIONES EXISTENTES}

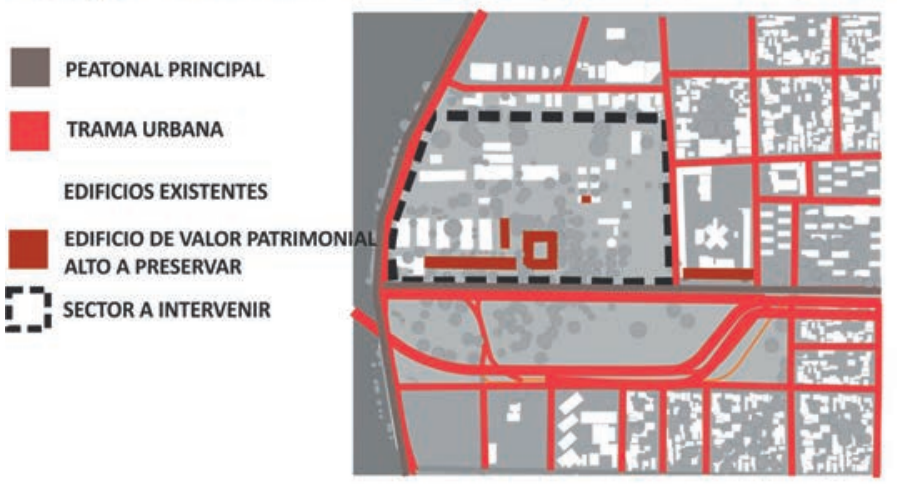

\section{ESQUEMA DE CIRCULACIONES PROPUESTA}

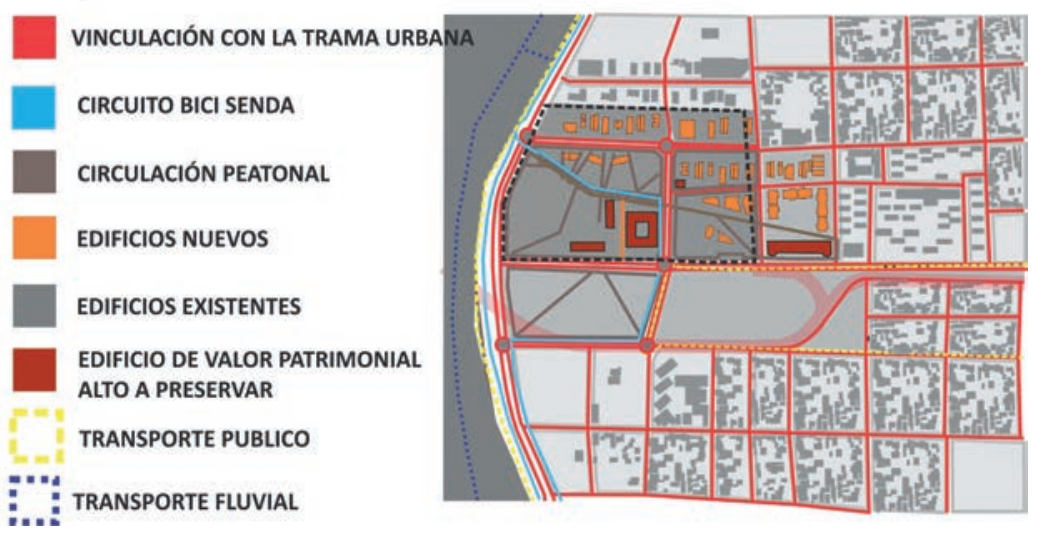

Esquema de situación actual y propuesta del sector Regimiento 


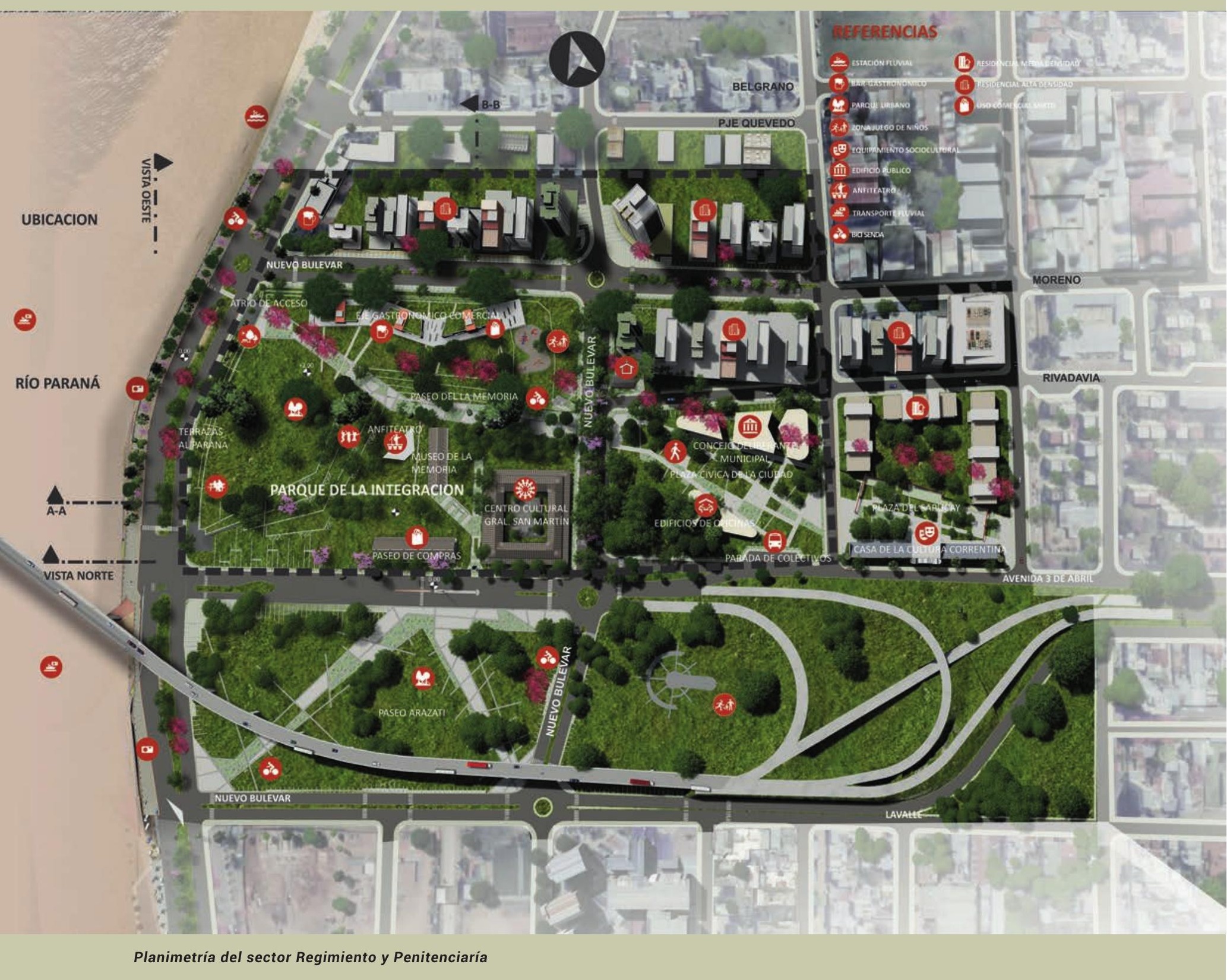


Para lograr un uso constante del espacio, se focalizó en la mixtura funcional con usos diferenciados y complementarios: espacios de recreación y culturales y edificios administrativos, de manera que el espacio sea vivido toda la semana. Se configuraron nuevas manzanas que completan los desarrollos existentes sobre Quevedo y las que resultan de las nuevas vialidades, dando soporte a los edificios de mayor altura. Un eje peatonal E-O hilvana las distintas actividades: el Concejo Deliberante, que se concibe como una pieza urbana inescindible de la plaza cívica, oficinas comerciales, el Museo de la Memoria, el Centro cultural Gral. San Martín, el paseo gastronómico, y remata en el mirador urbano. El paseo gastronómico se concibe con edificios que se abren al nuevo bulevar como al eje peatonal en el interior del parque, generando permeabilidad e integración visua entre la trama y el verde.

Se asignó a utilidad privada el $30 \%$ de la superficie del predio con una edificabilidad aproximada de 180.000 $\mathrm{m}^{2}$ en edificios residenciales en alta densidad con zócalo activo de actividades comerciales, complementarias y de servicios, tomando como referencia parámetros urbanísticos del distrito Re3 adyacente.

\section{Predio Penitenciaría}

Ubicado en el espacio de transición entre la trama urbana consolidada y el Parque de la Integración, funciona como nexo a partir del paseo centra sobre el que se organizan nuevas actividades. El predio hoy cerrado se perforó abriendo una calle vehicular y un pasaje peatonal que refuerzan la continuidad E-O. Las funciones previstas, residenciales, comerciales y socioculturales se concibieron con la intención de resignificar la connotación del uso carcelario y contribuir a la nueva centralidad propuesta.

El partido se organizó sobre un eje peatonal multipropósito que se prolonga hasta el Parque de la Integración, resolviendo el vínculo de continuidad entre Av. 3 de Abril y barrio Ferré con Costanera como parte de un paseo, que funciona como zona de transición entre la trama existente y el borde costero.

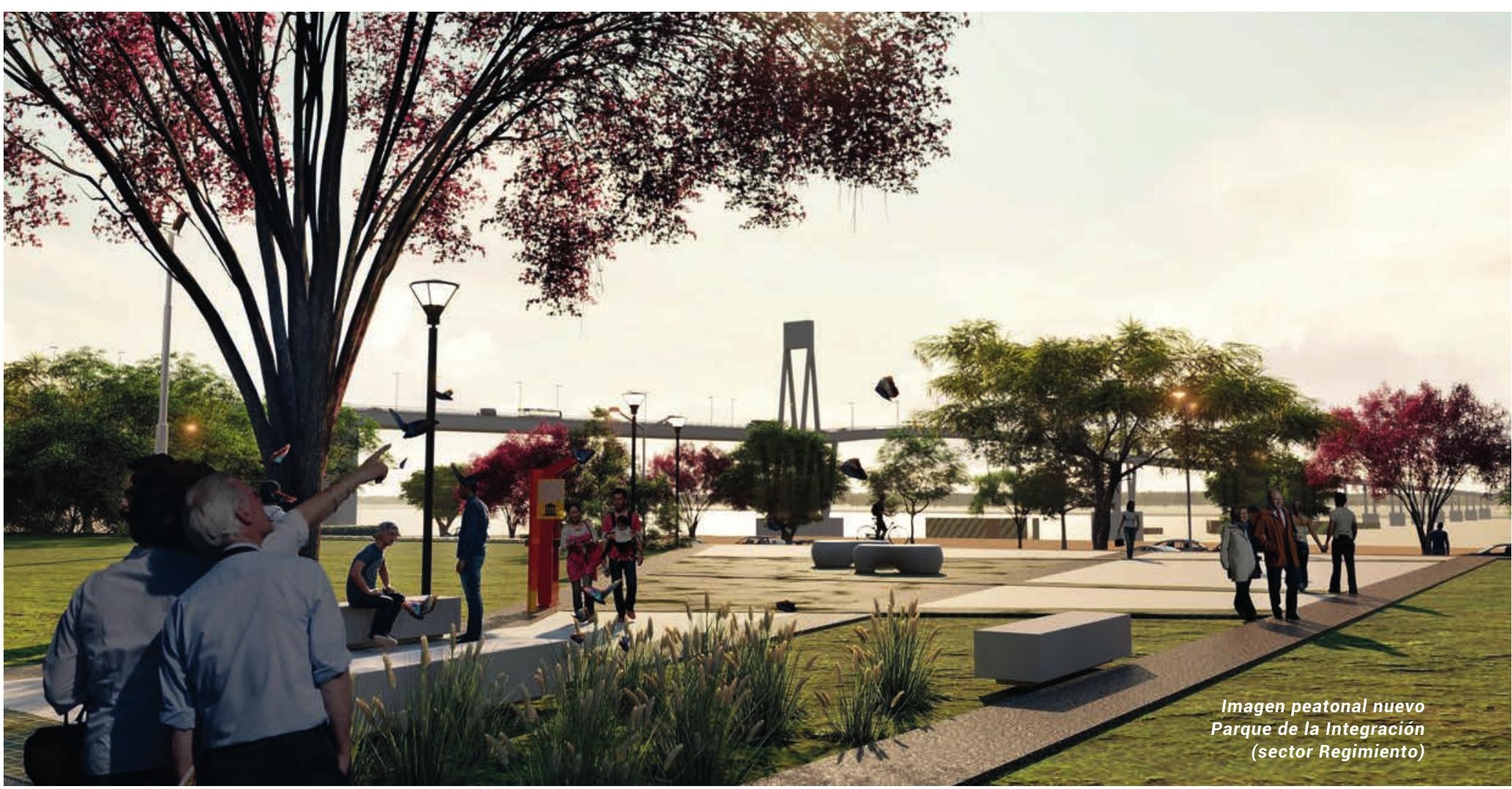




\section{Conectividad y movilidad}

A nivel vehicular se dio continuidad a la calle interna del barrio Ferré (prolongación de Rivadavia) para favorecer la gestión del tránsito, y a nivel peatonal se propuso la permeabilidad del actual edificio de la penitenciaría y el refuerzo de circulación en sentido este-oeste. Se incorporó un edificio de estacionamiento para aumentar la capacidad de soporte del área y servir a usos generales de la costanera.

La disposición de la forestación enfatizó el eje del paseo que comienza en el barrio Ferré y se proyecta en unión con el Parque de la Integración, combinando especies arbóreas autóctonas protagonizadas por el lapacho que caracteriza la costanera correntina. En general, se utilizaron arbustos bajos y plantas colocadas en macizos para reforzar áreas específicas.

\section{Usos y edificabilidad}

La mixtura funcional habilitará actividades en distintos horarios, aportando vitalidad a la zona. A nivel espacial, el área residencial marca dos situaciones: la manzana norte con parámetros urbanísticos de alta densidad ya presentes en la zona del pasaje Quevedo, pero con una subdivisión parcelaria en lotes

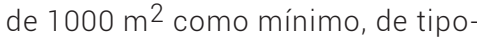
logía de semiperímetro y perímetro libre, a fin de evitar la formación de pantallas. En la manzana sur, edificios de media densidad dispuestos alrededor del espacio verde que funciona como área común. En ambos casos está previsto un zócalo activo para actividades comerciales y complementarias.

El edificio de alto valor patrimonial de la penitenciaría será refuncionalizado y destinado a usos socioculturales (Casa de la Cultura Correntina), para reconvertir un espacio de control y encierro en un sitio de uso colaborativo y público. La nueva actividad cultural se prolongó en el espacio público (plaza Sapucay), donde se proyectaron un anfiteatro y espacio de exposiciones.

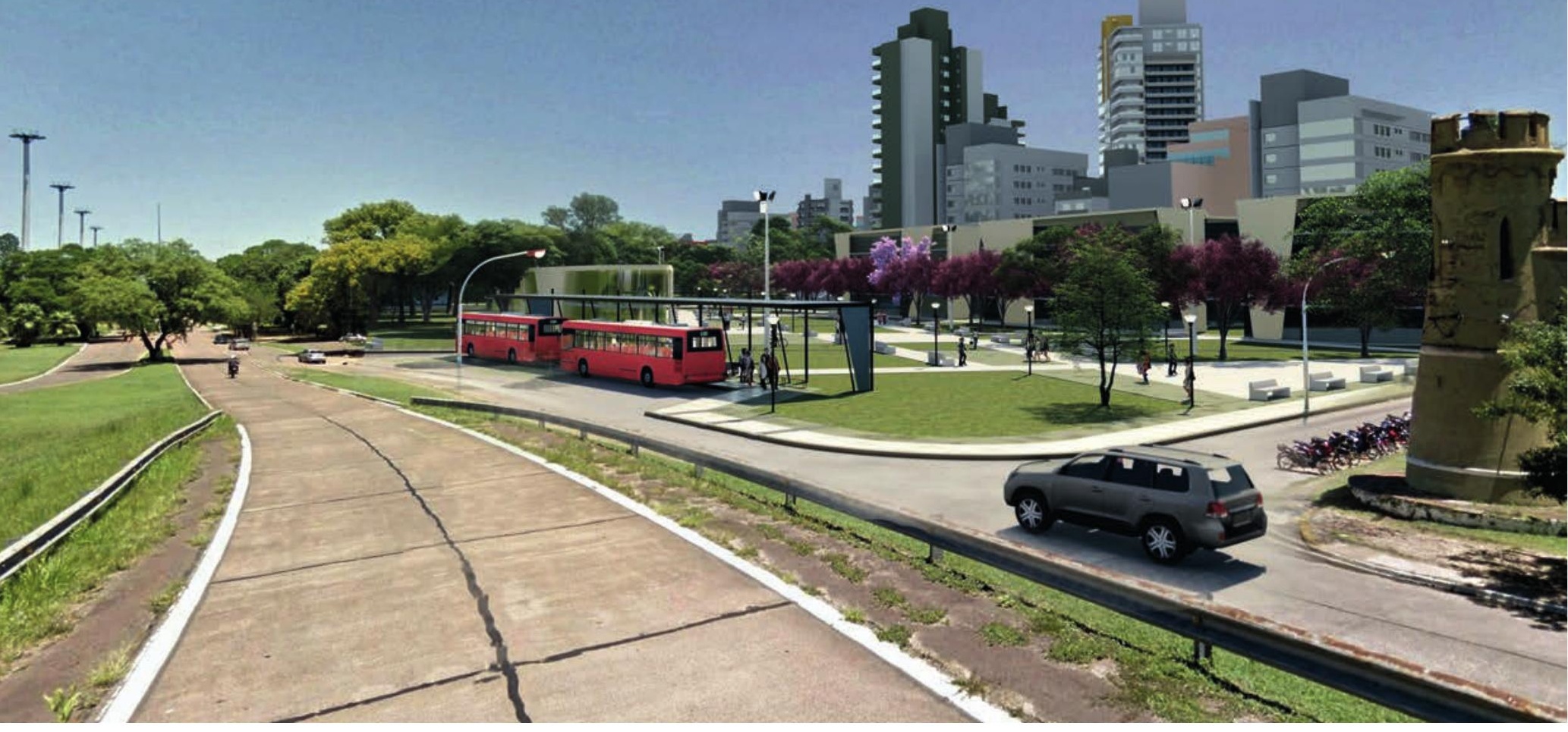




\section{ESQUEMA DE CIRCULACIONES EXISTENTES}

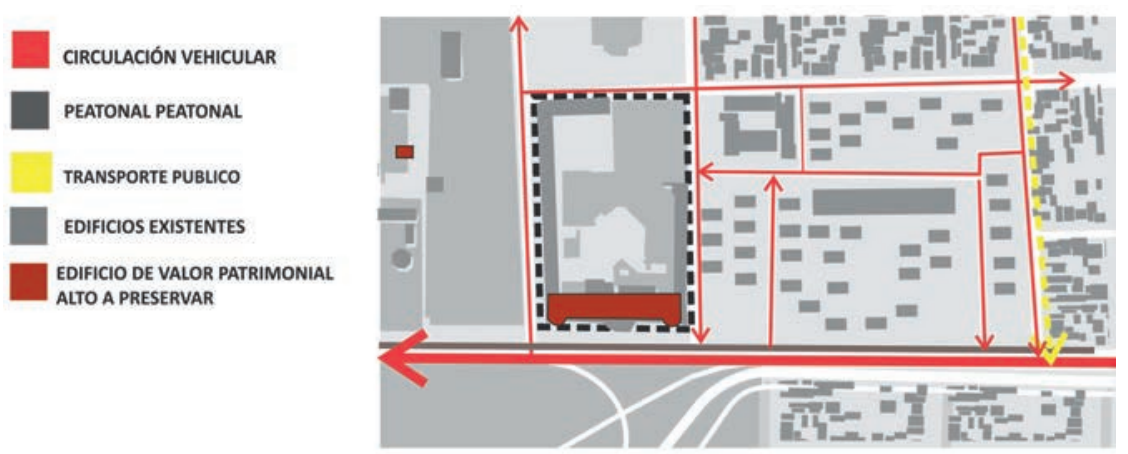

Esquema de situación actual y propuesta del sector Penitenciaría

\section{ESQUEMA DE CIRCULACIONES PROPUESTAS}

CIRCULACIÓN VEHICULAR

CIRCULACIÓN PEATONAL

TRANSPORTE PUBLICO

EDIFICIOS NUEVOS

EDIFICIOS EXISTENTES

EDIFICIO DE VALOR PATRIMONIAL ALTO A PRESERVAR

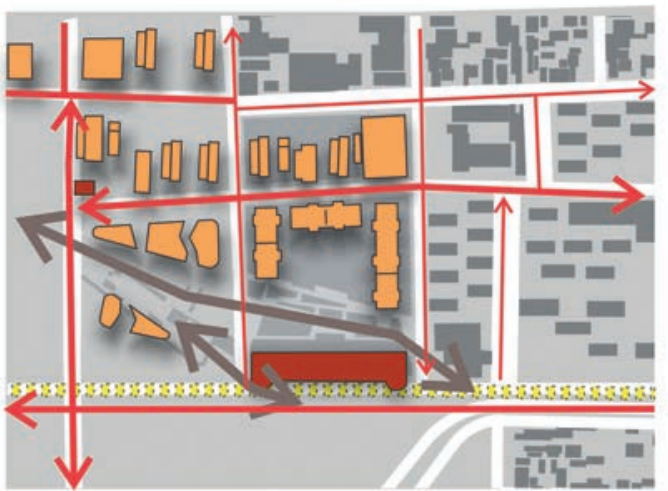

Imagen aérea sector Penitenciaría

*
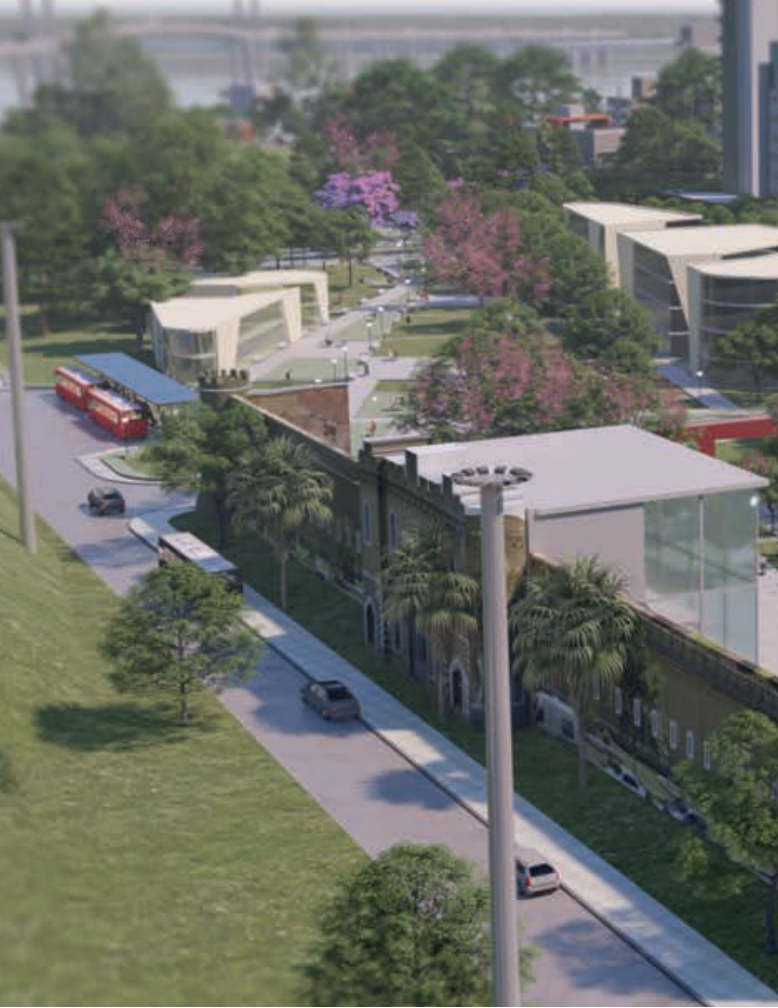

a
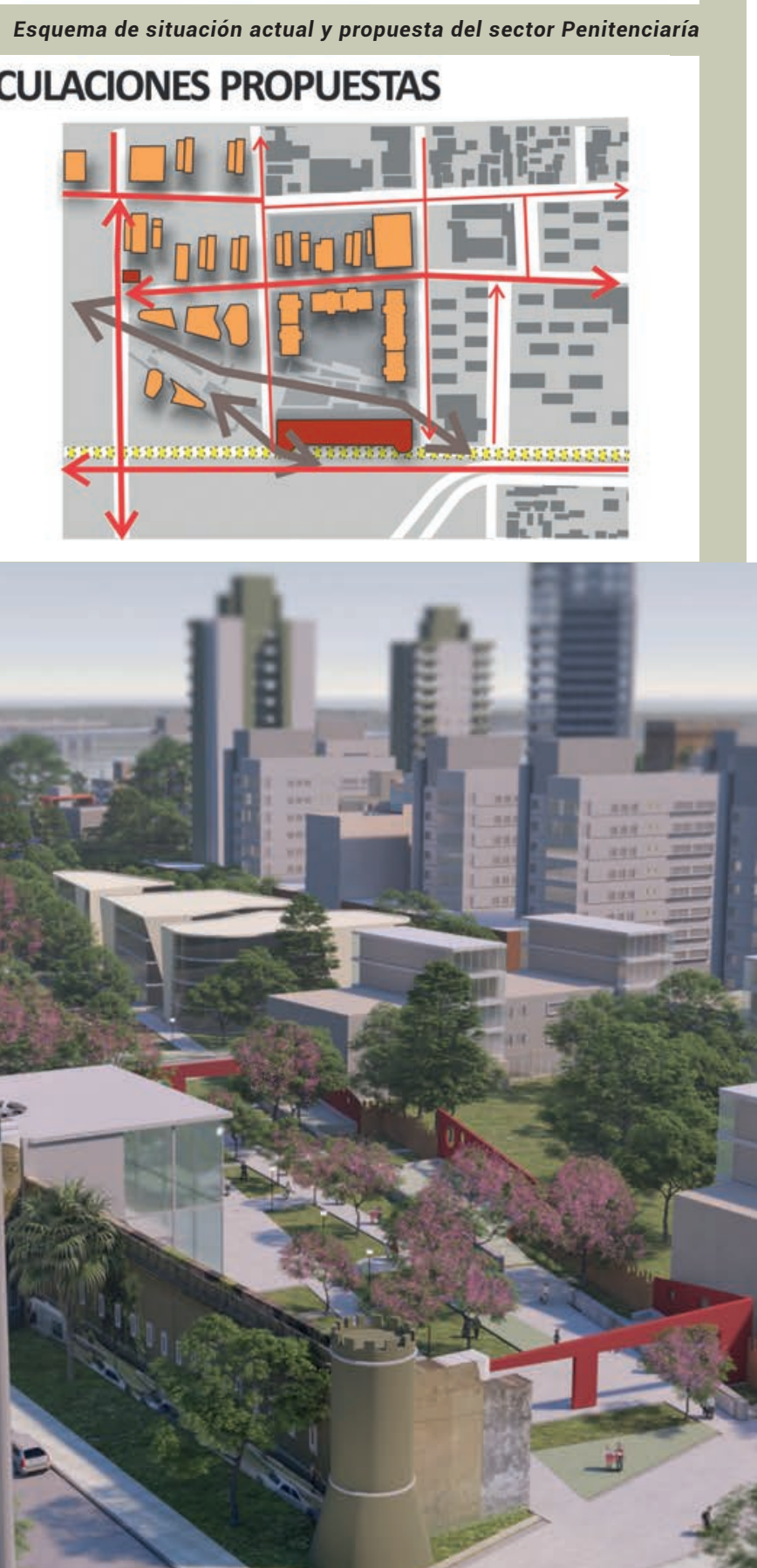